They indicated that oxidation does not occur at the unsaturated bond, according to the long-accepted theory, but at a $\mathrm{C}-\mathrm{H}$ bond. Hydroperoxides are formed and can be isolated in certain cases. After the preliminary formation of a hydroperoxide, the course of the oxidation is governed by its decomposition. There is much evidence that ketones are the key decomposition products from which the more highly oxidized compounds are derived. Hydroperoxide formation in both thermal and catalysed reactions proceeds by a chain mechanism. Whereas the catalysed reactions involve free radicals as the chain carriers, there is some evidence that in the thermal reaction the chain carriers can be free radicals or energy-rich molecules, depending on the particular hydrocarbon which is oxidized. In the uncatalysed oxidation the auto-catalytic increase is due to a hydroperoxide catalyst reaction developing side by side with the thermal oxidation.

It should not be too difficult, now that our know. ledge of oxidation is improving rapidly, to predict the stability to oxidation of a pure hydrocarbon of known structure. Apparently, the oil starts to oxidize almost uncatalysed, and as acids are produced they gradually dissolve away various catalytic metals and so catalytic oxidation proceeds.

Anti-oxidation has long been known, but there is a shyness, or perhaps distrust, towards it among makers of transformer oil.

E. A. Evans stated in his paper that the time is at hand when broad principles must be introduced, studied and applied. Caution can be observed, provided it does not decelerate progress. If oxidation of transformer oil is objectionable, any method by which it can be reduced is worthy of consideration; fear that a method is transitory is insufficient to condemn it. Chemical additives have been introduced and are now standardized in many industries, as well as in certain branches of the petroleum industry, particularly lubricants which are akin to transformer oil. How the petroleum industry is attracted to anti-oxidants is revealed in this paper.

Probably no one is perfectly happy with the many methods which have been suggested for measuring the propensity of an oil to oxidize; but C. H. Barton feels that the sludge test for transformer oils as practised in Great Britain is too unreliable in its present form, and, of course, he gave supporting evidence for his attack.

A. A. Pollitt, in his paper, reviewed the oxidation tests for transformer oil which are practised in other countries and indicated that they possess no general advantage over the British method. This comparison and criticism is a very useful contribution as it emphasizes the difficulties of the problem.

Messrs. Gossling and Romney gave a paper which showed fairly conclusively that even an apparently small difference, such as variation of the water temperature in the condenser, has a profound effect upon the amount of oxidation produced.

Mr. Norris, in the discussion which followed the papers, speaking as a transformer engineer of many years experience, suggested that insufficient attention has been given to the insulating material in a transformer other than oil. $\mathrm{He}$ felt that the insulating varnish has a considerable effect upon the decomposition of the oil. His view appeared to be that if varnish were excluded much of the trouble would be eliminated.

Collected information by the Incorporated Municipal Electrical Association was presented by D. P.
Sayers. This was based upon replies to a questionnaire issued to twenty-two large municipal undertakings, which have some ten thousand transformers in service ranging in size from $5 \mathrm{kVA}$. to $4,000-5,000$ $\mathrm{kVA}$., aggregating in all more than 6 million $\mathrm{kVA}$. It is significant that in less than 2 per cent of the ten thousand transformers has any acid trouble been experienced. More than 90 per cent of the troublesome transformers were filled with Class A oil. The information received as to the effect on the transformer of high acid values in the oil is far from onsistent. The principal effect is on the inside of the lid and tank sides above oil level. Although this occurs with high acid values, instances were given of attack with values less than $1 \mathrm{mgm}$./KOH. In the majority of cases the acid appears to have no direct deleterious effect on the insulating materials or copper windings. When once acidification has started, however, the process continues.

A. G. Ellis confirmed that sludge is not a matter for much anxiety these days. Acid trouble has been practically confined to Class A oil. Neither C. W. Marshall, who is mainly interested in the Class B oils in large transformers, nor L. H. Welch, whose principal concern is small transformers, had any serious criticisms to make about large transformers. Possibly this is mainly due to the great care taken in their maintenance; small transformers should be given more attention.

R. Weaving reminded the meeting that there was trouble fifteen to twenty years ago, but undoubtedly there has been an improvement in the quality of the oil and in the design of transformers, particularly in the elimination of hot spots or, as the chemist would prefer to say, hot zones. Very few transformers are on full load continuously, therefore we should reconsider the subject of temperature, particularly in the testing of oil. The pre-eminence given to acid at the present time may be one of those cycles of fashion which occur; on the other hand, it may be due to want of appreciation of the value of ventilation.

F. Meyer was of the opinion that too much blame should not be put upon the insulating varnish. After all, there are different kinds of varnish and different ways of processing it.

A full report of the symposium will appear shortly in the Journal of the Institute of Petroleum.

\section{WHAT IS THE TRUE SHAMROCK?}

\author{
By Dr. HUGH O'NEILL \\ Langlois Herbarium, Catholic University of America, \\ Washington, D.C.
}

$7 \mathrm{HE}$ earliest mention of the word 'shamrock' in English literature as given by the Oxford Dictionary $(8,622-23 ; 1914)$ is in Campion's "History of Ireland", 1571. Other early occurrences of "shamrock' given by the same authority are in the writings of Stonyhurst, 1577 ; Spenser, 1596 ; Holland, 1610; Withers, 1613 and 1633 ; and Moryson, 1617. From these authors it is clear that the plant designated by them 'shamrock' : (1) grew in the woods of Ireland; (2) grew in association with water-cress; (3) had a sour taste; and (4) was commonly eaten by man.

Of all the plants wrongly or rightly identified with the shamrock, only one has all these four char. acteristics. It is the wood-sorrel (wood-sour or woodsower), Oxalis Acetosella L. This plant is certainly 
the shamrock of these English authors, and from their usage it has become the shamrock of English literature.

On the other hand, the shamrock commonly worn on St. Patrick's Day is the small hop-clover, Trifolium dubium (=T. minus Smith). This is the plant generally sent as the shamrock to the United States from Ireland; it is the plant mentioned as the shamrock in the "Encyclopedia Britannica", 14th edition (Article "Clover", 5, 854d; 1929) and in the Oxford Dictionary (p. 623), which states that "The name is now commonly applied to the lesser yellow trefoil, Trifolium minus, which is the plant commonly worn as an emblem on St. Patrick's Day".

Various attempts have been made to explain this discrepancy. Perhaps the most widely accepted conjecture in botanical literature is in Bonplandia (1, 50-51; 1853. Hannover) under the heading "Vermischtes" where the [London] Daily Express is quoted in German translation. Here attention is directed to the fact that Ireland in earlier times was predominantly wooded, that is, it was the habitat of the wood-sorrel. Later, as the woods gave place to cultivated or pasture lands, the wood-sorrel likewise gave place to the white or Dutch clover, Trifolium repens, and the name shamrock was accordingly transferred to this inhabitant of the cultivated fields.

This surmise, commonly accepted in botanical circles (for example, Hegi, "Illustrierte Flora von Mitteleuropa $I V^{3}{ }^{3 \prime}$ : 1306, 1650, 1654; 1924, where Trifolium repens is said to be the present-day shamrock), is open to serious objection on botanical grounds and is contradicted by linguistic evidence. While it is safe to assume that Ireland, like all other countries of the cool temperate zone with an annual rainfall of more than fifteen inches, was originally covered mostly with forest, yet it is equally certain that many small areas throughout Ireland never could have supported the growth of trees; for example, areas where the layer of soil was very thin, especially where the ice-sheet of glacial times had denuded the hill-tops or localities where the sub-soil was too porous to hold the abundant rainfall (for example, on moraines, eskers, drumlins and sand-dunes) or districts where the forest-growth was destroyed by man or other agencies. Such areas are the habitats of the clovers which must therefore have been common enough in Ireland even in the earliest times ; hence both wood-sorrel and clovers were always common in Ireland; their relative abundance changing from time to time is no reason why the name shamrock should have been transferred from one plant to the other.

A study of the history of plant names shows that people living close to the soil have a very accurate knowledge and nomenclature of the plants of their surroundings and do not readily transfer names from one plant to another so different as the sour woodsorrel is from the sweet clover, without adding a qualifying adjective that will prevent confusion. Old names for wood-sorrel in English are 'ladies' clover', 'sour trefoil', but not clover or trefoil without the qualifying adjective. Similarly, in German this plant is commonly called 'Sauer-klee' or 'Wald-klee', while 'Klee' alone means clover. Finally, in Irish, 'seamar' or 'seamrog' means trefoil, elover or shamrock; while 'seamar coille' and 'seamar gear' mean respectively wood-clover and sour-clover, that is, English woodsorrel. Dineen ("Irish-English Dictionary", 2nd edition, Dublin, 1927) correctly states this last plant is "the shamrock of the Elizabethan writers".
Evidently once Campion had mistakenly identified the shamrock as the wood-sorrel, later English authors followed him. In Scotland, however, this mistake did not occur. All early Scotch Gaelic dictionaries translate 'seamar' and 'seamrag' as clover or trefoil, only one of the recent dictionaries giving wood-sorrel as a second meaning. (Shaw, "A Gaelic and English Dictionary", 1780, London; "A Dictionary of the Gaelic Language", 2 vols., 1828, Edinburgh and London, pub. by the Highland Society of Scotland; Macleod and Dewar, "A Dictionary of the Gaelic Language", 1901, Edinburgh, all give trefoil or clover as the meaning of 'seamrag'. "A Gaelic Dictionary", published by E. Macdonald and Co., Herne Bay, 1902 , gives trefoil or clover as the meaning of 'seamrag' but adds as a second meaning wood-sorrel.) As a latest, most convincing Scottish source, taken directly from the living language uninfluenced by literature, there is "A Pronouncing Dictionary of Scottish Gaelic, based on oral information of natives born before the middle of the last century in the Glengarry District", by Henry Cyril Dieckhoff, O.S.B., Edinburgh, 1932. Only one meaning of 'seamrag' is given, namely, clover. ("A Pronouncing and Etymological Dictionary of the Gaelic Language", Malcolm Maclennan, Edinburgh, 1925, gives wild clover as the meaning of 'seamair' and shamrock as the meaning of 'seamrag'.)

In Irish dictionaries, trefoil or clover is always given as the first meaning of 'seamrag'. In some works wood-sorrel is given as a second meaning. Conversely, the first Gaelic word given for wood-sorrel is 'seamsog' not 'seamrog'. 'Seamsog' never means clover. In the Irish alphabet the character for ' $r$ ' is similar to that for ' $s$ '. This resemblance may explain how Campion confused one with the other.

Finally, the word seamar exists in Old Irish as semar with the meaning of trefoil or clover (Hogan, Hogan and Macerlean, "Irish and Scotch Gaelic Names of Herbs, Plants and Trees", Dublin, 1900 ; Alexander Macbain, "An Etymological Dictionary of the Gaelic Language, Stirling, 1911, give 'semmor' as the Early Irish form.)

Regarding the addition of the suffix '-og' to 'semar', George Calder states ("A Gaelic Grammar", Glasgow, 1923 ) this is a loan ' $k$ ' suffix developed from Brythonic sources and in support cites Lewis and Pedersen ("A Concise Comparative Celtic Grammar", 29, Göttingen, 1937). Gerald O'Nolan ("The New Era Grammar of Modern Irish", 232, No. 18, Dublin, 1934) discusses '-og' as a suffix.

There is no evident earlier trace of 'semar' than Old Gaelic. Welsh, Cornish and Breton dictionaries show no Brythonic cognate for semar or seamrog. Further, no Indo-european root is given by Pokorny (Alois Walde, "Vergleichendes Wörterbuch der Indogermanischen Sprachen", Berlin and Leipzig, 192732) for the word shamrock. It may possibly be a pre-Celtic word. There seems to be no evidence of Druidical use of the shamrock as an emblem or in association with any ritual. Clover-leaf needles or stilettos (Klee-blatt Nadeln) have been found in the Pyrennean Megalithic Period or early Bronze Age in France (Ebert, "Real Lexicon d. Vorgeschichte IV ${ }^{1 "}, 30$; 1926), but can scarcely be construed as predecessors of the shamrock as an emblem. Dineen (op. cit.) offers the interesting suggestion that the shamrock is "possibly a survival of the trignetra, a christianized wheel or sun symbol".

The antiquity in historic times of the emblematic use of the shamrock is established by the Rev. James 
Forrestall in "The Shamrock Tradition" (Irish Ecclesiastical Record, 36, 63, 1930, Dublin).

As to which species of clover is the shamrock, the overwhelming majority of the Irish consider the small yellow-flowering trefoil as the shamrock. This usage of the people of Ireland has the force of a living tradition and outweighs the evidence of some of the dictionaries and lexicons which refer the shamrock to Trifolium repens, the white or Dutch clover. Botanical names, unless used by systematic botanists, are often misapplied. The plant meant by the people of Ireland has much greater claim to accuracy than a botanical name in a dictionary. Mgr. Patrick Nolan, Lakeland, Florida, recalls that as a boy in Belfast he learned to distinguish the shamrock from the clover (T. repens) by the white spots commonly shown on the leaves of the latter. T. dubium does not have white-spotted leaves.

To sum up : the shamrock of Irish and Scotch Gaelic language and literature and tradition is a clover, in the living tradition of the Irish, Trifolium dubium Sibth. The shamrock of English writers is the wood-sorrel.

\section{NEW CROP VARIETIES}

$\mathrm{N}^{\mathrm{BV}}$

EW introductions from Sweden, Denmark, Holland, France, Canada and the United States are included among the 163 distinct varieties and strains of crop plants now being tested by the National Institute of Agricultural Botany, Cambridge. Many very promising varieties have been submitted by private and 'official' plant breeders working in England, Wales, Scotland and Northern Ireland. In order to give the varieties every opportunity of demonstrating their merits, the fifteen principal yield trials are repeated at centres as far apart as Newcastle-on-Tyne, Bridgwater, and Wye (Kent).

To secure accurate yield results the Institute normally includes each variety in eight different plots, while seasonal effects are overcome by continuing the trials for three seasons in succession. Among the 98 varieties included in special observation plots are fourteen French varieties of wheat submitted by the Syndicat des Producteurs de Semences Selectionnées which are growing alongside the well-known variety Bersee.

Resistance to attacks of such diseases as yellow rust and loose smut, as well as 'lodging' of the straw in cereals, are carefully watched, and the most successful varieties will be promoted from observation plots to yield trials in 1947.

The quality of the resulting crop is carefully studied in co-operation with interested authorities such as the Cereals Research Station at St. Albans, and the Institute of Brewing. The progress made in the breeding of higher quality varieties of oats, wheat, barley, potatoes and sugar beet, etc., is largely the result of careful testing of older varieties in past years.

Apart from the headquarters trial ground at Cam. bridge, three of the pre-war testing stations are now in full progress at the Harper Adams College (Shropshire), Cannington Farm Institute (Somerset), and the Norfolk Agricultural Station at Sprowston. New regional stations have been established with the approval of the Ministry of Agriculture at the following centres: King's College Farm, Nafferton, Newcastle-on-Tyne; Midland Agricultural College
Farm, Loughborough; Hampshire Farm Institute at Sparsholt; and the South-Eastern Agricultural College at Wye. In Yorkshire, trials have been distributed between the Askham Bryan Farm Institute and selected farms in the Wolds and Holderness districts of East Riding.

Combine harvesters will be used to harvest many of the trials in Cambridge, Norfolk and Yorkshire. The 'Combine' enables additional trials to be conducted on farms possessing soil or climatic conditions which are of special interest but which are situated at some distance from a testing station.

The following members of staff have recently been appointed to the National Institute of Agricultural Botany : Mr. J. C. Cullen, senior scientific officer in charge of potato trials and propagations; Dr. F. Earnshaw, economic botanist; and Messrs. P. J. Jones, A. F. Kelly, G. W. Mann, L. A. Willey, A. Main, G. G. Graham, J. D. Ivins and J. Munro, crop recorders at the trial centres.

\section{EXPLORING MAGNETIC FIELDS}

A $\mathrm{N}$ article by Lillian Shapiro (Bell Lab. Rec., 23, No. 8; August 1945) describes means and methods devised for exploring the magnetic fields employed for guiding the electron stream in a cathode ray tube. Search coils are used in the method and a special winding machine and technique were developed to produce them.

Two coils with the axis of one at right angles to that of the other are wound on a common mandrel, and this assembly, with an outside diameter of about 0.2 in., is slipped into the end of a very thin-walled plastic search tube in such a way that one of the coils is concentric with the tube. As this search tube is moved along the axis of the tube, this latter coil will always be in a position to measure the component of the flux along the $z$-axis, while the other coil may be used to measure the components along the other two axes, turning the tube first so that the coil is perpendicular to the $x$-axis and then turning it $90^{\circ}$ to bring it perpendicular to the $y$-axis.

Since such a search tube cannot actually be inserted in a cathode ray tube, exactly equivalent conditions are simulated by using a solid plastic cylinder with an outside diameter the same as the cylindrical section of the cathode ray tube. This plastic cylinder is accurately drilled longitudinally with twenty-one holes. It is then slipped inside the deflexion assembly of the cathode ray tube just as the tube itself would be. The magnetic fields set up in the plastic cylinder are thus exactly the same as those in a cathode ray tube when the same deflexion assembly is used.

The search tube carrying the exploring coils is inserted successively in the twenty-one holes of the cylinder, and a number of readings is taken in each so as to record the field at successive positions along the length of the tube. At each position, a reading on the coil that is concentric with the tube gives the $z$ component of the field. Readings of the $x$ - and $y$-components are made with the transverse coil, which may be rotated to any desired position merely by turning the tube. On the end of the tube remote from the exploring coils, there is a protractor from which the $x$ - and $y$-axes may be determined.

One of the holes in the plastic block is exactly down the centre. The maximum field in this hole is usually rectilinear, with a component along one axis 